\title{
Improved thermal features and ionic conductivity of lithium-zinc-tellurite glass electrolytes
}

\author{
W. Widanarto ${ }^{1}$, M. R. Sahar ${ }^{2, *}$, S. K. Ghoshal ${ }^{2}$, Mashadi ${ }^{3}$, D. Gustiono ${ }^{4}$, M. Effendi ${ }^{1}$ \\ ${ }^{1}$ Department of Physics, Universitas Jenderal Soedirman, Jl. dr. Soeparno 61 Purwokerto 53123, Indonesia \\ ${ }^{2}$ Department of Physics, AOMRG, Universiti Teknologi Malaysia, Johor Bahru, Skudai 81310, Malaysia \\ ${ }^{3}$ PSTBM - BATAN, Kawasan Puspiptek Serpong - Tangerang Selatan 15314 \\ ${ }^{4}$ BPPT, Center of Materials Technology, Jl. MH. Thamrin 8 Jakarta - Indonesia \\ *Corresponding Author: rahimsahar@utm.my
}

\section{Article history :}

Received 21 October 2014

Revised 15 November

Accepted 29 November

Available online 1 December 2014

\section{GRAPHICAL ABSTRACT}

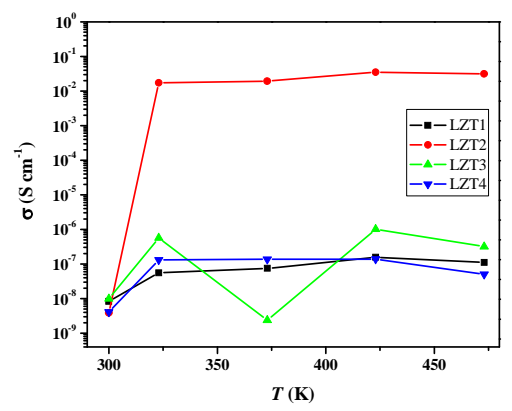

\section{ABSTRACT}

Synthesizing glass electrolytes with modified ionic conductivity by incorporating $\mathrm{Li}_{2} \mathrm{O}$ for enhanced secondary battery safety is ever-demanding. Electrolytes based on zinc-tellurite glasses with chemical composition $(85-x) \mathrm{TeO}_{2} \cdot x \mathrm{Li}_{2} \mathrm{O} \cdot 15 \mathrm{ZnO}$, where $x=0,5,10,15 \mathrm{~mol} \%$ are prepared using melt quenching method. The temperatures, frequency and $\mathrm{Li}_{2} \mathrm{O}$ concentrations dependent modifications of structural features, thermal stability, and ionic conductivity are determined. Amorphous nature of electrolytes is verified from X-ray diffraction patterns. Incorporation of $\mathrm{Li}_{2} \mathrm{O}$ in the electrolytes is found to decrease the glass transtition temperature from 318.41 to $280.63{ }^{\circ} \mathrm{C}$ leading to their thermal stability enhancement. Alternating current impedance measurement revealed that the ionic conductivity of the electrolytes is significantly influenced by the temperature and concentration of $\mathrm{Li}_{2} \mathrm{O}$ and not by the frequency of AC voltage. The glass electrolyte containing $5 \mathrm{~mol} \%$ of $\mathrm{Li}_{2} \mathrm{O}$ exhibited good performance with the ion conductivity of $1.72 \times 10^{-2} \mathrm{~S} \mathrm{~cm}^{-1}$ and activation energy of $3.85 \times 10^{-1} \mathrm{eV}$. These improvements in the conductivity and activation energy are attributed to the alteration in ions vibration and breakage of covalent bonds. This modification allowed the ions to move through un-perfect nonbridging oxygen under the influence of an external electric field (applied voltage) with enhanced mobility. The present glass electrolyte is very promising for secondary Li-ion battery fabrication.

Keywords: tellurite, glasse, differential scanning calorimetry, ionic conductivity, activation energy.

(C) 2014 Penerbit UTM Press. All rights reserved http://dx.doi.org/10.11113/mjfas.v10n4.363

\section{INTRODUCTION}

Batteries with inorganic solid electrolytes and electrodes are highly promising for sundry applications due to their safety, long life cycle, and versatile geometry. A lithium ion (Li-ion) battery being the rechargeable one is interesting because its discharge capacity is much better than conventional batteries with very high power density $[1,2]$. It is safe and durable, and requires electrolytes that can withstand high temperatures and applied voltage offering high mobility for Li-ions. The use of liquid electrolytes in the Li-ion batteries have a high risk of fire danger because most of liquid electrolytes are organic solutions $\left(\mathrm{LiBC}_{4} \mathrm{O}_{8} \quad(\mathrm{LiBOB}), \mathrm{LiPF}_{6}, \quad \mathrm{Li}\left[\mathrm{PF}_{3}\left(\mathrm{C}_{2} \mathrm{~F}_{5}\right)_{3}\right]\right)$, which are flammable. Inorganic solid electrolyte conductive Li-ion is an attractive material to be developed not only because it is safe from fire hazards but also stable against Li-ions $[3,4]$. The solid electrolyte must be highly conductive, compatible with the electrode material (such as lithium metal) as well as physically and chemically stable in air atmosphere. In addition, it must be easily prepared at low temperatures [5].

Definitely, a glass has high potential to be used as a solid electrolyte in the Li-ion batteries because of several advantages compared to solid electrolyte crystals [6,7]. The advantages of the glass electrolytes include broad range of composition selection, isotropic properties, no grain boundaries, facile synthesis both at low and high temperatures as well as the easy control of parameters. It is acknowledged that lithium borosilicate and sulfide glasses displaying good ionic conductivity performance is suitable for battery construction $[5,8,9]$.

Zinc-tellurite $\left(\mathrm{ZnO}-\mathrm{TeO}_{2}\right)$ glass is easy prepare and stable due to the formation of $\mathrm{ZnTeO}_{3}$ structural units $[10,11]$. Besides, this glass system has a low melting temperature. Therefore, this study focuses on the development of zinc-tellurite glass as a solid electrolyte in lithium ion secondary batteries. Glasses are made via melt quenching method. Optimization of glass-formation, glass modifiers and lithium ion composition are performed to 
determine the ionic conductivity and durability of glass. Glass electrolytes are characterized to determine their ionic conductivity and activation energy.

\section{EXPERIMENTS}

Glasses of the form $(85-\mathrm{x}) \mathrm{TeO}_{2} \cdot \mathrm{xLi}_{2} \mathrm{O} \cdot 15 \mathrm{ZnO}$ with $x=0,5,10,15 \mathrm{~mol} \%$ are prepared using melt quenching method [11,12]. To achieve efficient solid glass electrolytes, commercial $\mathrm{TeO}_{2}\left(99+\%\right.$, Acros), $\mathrm{ZnO}_{2}$ (99.5+, Acros) and $\mathrm{Li}_{2} \mathrm{O}$ (99\%, Sigma Aldrich) powders of analytical grades are used as starting materials, manually mixed in a ceramic crucible and melted in an electrical furnace (WiseTherm) at $800{ }^{\circ} \mathrm{C}$ for $20 \mathrm{~min}$. Then, the melt is immediately poured on pre-heated bronze mold on hot plate (Heidolph MR $3001 \mathrm{~K}$ ) and pressed using other heated metal plate. The quenched melt is annealed at 300 ${ }^{\circ} \mathrm{C}$ for $3 \mathrm{~h}$ and naturally cooled down to room temperature. Finally, the obtained glass electrolytes are milled and manually pressed to form pellets with diameter of $10 \mathrm{~mm}$ and thickness of $2 \mathrm{~mm}$.

X-ray diffraction measurement (XRD-Shimadzu $\mathrm{XD}-610)$ with $\mathrm{Cu}-\mathrm{K} \alpha$ radiation $(\lambda=1.54 \AA)$ is employed to ensure the glassy nature of electrolytes. Thermal properties of the electrolytes are studied using differential scanning calorimeter (DSC-Perkin Elmer) in the temperature range of $240-447{ }^{\circ} \mathrm{C}$. The ionic conductivity of the electrolytes as function of frequency are determined using the ac impedance method. The AC impedance data is aquired at a voltage of $1.5 \mathrm{~V}$ in the frequency range of $1-100 \mathrm{kHz}$ using LCR meter (HIOKI 3522-50). Meanwhile, the temperature and concentration dependent ionic conductivity as well as the changes in activation energy in temperature range of 300-473 K are determined.

\section{RESULTS AND DISCUSSION}

The XRD patterns of the prepared glass electrolytes as presented in Fig. 1 in the presence of a broad hump over the region $2 \theta=20-35^{\circ}$ without any typical Bragg peaks clearly reveal their amorphous nature. Furthermore, the patterns are similar to the previous reports [13-15].

Fig. 2 displays thermal response of the glass electrolytes. Depending on electrolytes compositions a shift in the glass transition $\left(T_{g}\right)$ and crystallization $\left(T_{c}\right)$ peaks is evidenced. The zinc tellurite glass electrolyte has glass transition temperature $T_{g}$ at $318.41{ }^{\circ} \mathrm{C}$ (midpoint value). $T_{g}$ of the electrolyte is found to decrease from 318.41 to $280.63{ }^{\circ} \mathrm{C}$ with the increase of $\mathrm{Li}_{2} \mathrm{O}$ from 5 to $15 \mathrm{~mol} \%$. Meanwhile, enthalpies of transition are increased from 6.68 to $23.44 \mathrm{~J} / \mathrm{g}$ as $\mathrm{Li}_{2} \mathrm{O}$ content is increased from 5 to 10 mol\%. The electrolyte became less viscous with increasing temperature as expected. At some point, the molecules may obtain enough freedom of motion to spontaneously arrange themselves into a crystalline form (exothermic process) which is signified by the value of $T_{c}$. $T_{c}$ of the electrolytes is observed to be about $410{ }^{\circ} \mathrm{C}$ with transition enthalpy of
-600 J/g, except the electrolyte containing $15 \mathrm{~mol} \%$ of $\mathrm{Li}_{2} \mathrm{O}$. The crystallization is not occurred in the temperature range of measurement. Thermal stability factor $\Delta T=T_{c}-T_{g}$ of the electrolytes containing $\mathrm{Li}_{2} \mathrm{O}$ is found to be higher than $100{ }^{\circ} \mathrm{C}$. It is worth noting that the incorporation of $\mathrm{Li}_{2} \mathrm{O}$ in the electrolytes in fact decreased the glass transition temperature, indicating the easy preparation of electrolytes at low temperature and their improved thermal stability due to the presence of non-bridging oxygen (NBO).

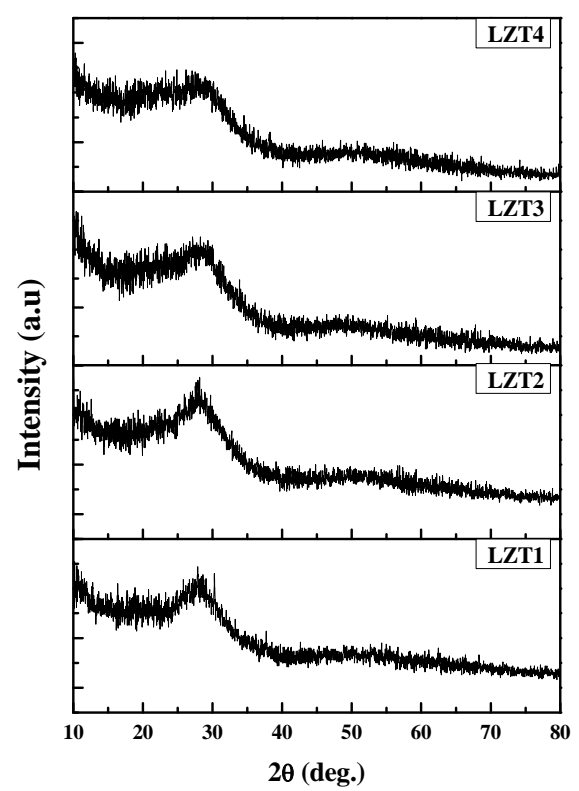

Fig. 1. XRD patterns of the glass electrolytes containing various $\mathrm{Li}_{2} \mathrm{O}$ concentrations

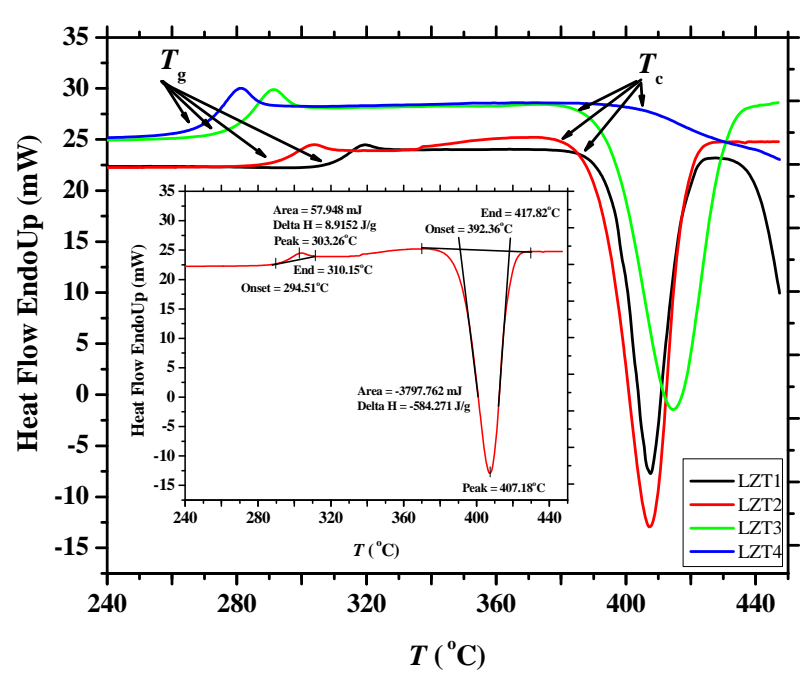

Fig. 2. $\mathrm{Li}_{2} \mathrm{O}$ concentrations dependent DSC thermograms of the prepared glass electrolytes. 
Fig. 3 illustrates the temperature dependent ionic conductivity for the glass electrolytes at frequency of 54 Hz. At room temperature ( $300 \mathrm{~K})$, the conductivity of the all electrolytes remains the same. However, the increase in temperature does not significantly affect to the conductivity of the LZT1, LZT3 and LZT4 electrolytes. The conductivity of LZT2 is found to be considerably influenced by the temperature variation, increased from $3.85 \times 10^{-9}$ to $3.49 \times 10^{-2} \mathrm{~S} \mathrm{~cm}^{-1}$ for temperature up to $423 \mathrm{~K}$. Under thermal equilibrium, the Li-ions are held by a weak covalent bond to zinc-tellurite. Increasing temperature generated thermal vibration of the ions and caused the rupture of bonds. Accordingly, the ions easily moved in the electrolyte and accelerated along the field upon applying a small electric field (AC voltage). Consequently, the ionic mobility increases followed by the conductivity enhancement [16,17]. Conversely, the decrease in conductivity above $423 \mathrm{~K}$ is interpreted as follows: the increase in temperature increased the vibration, leading to decreasing the mobility and the conductivity.

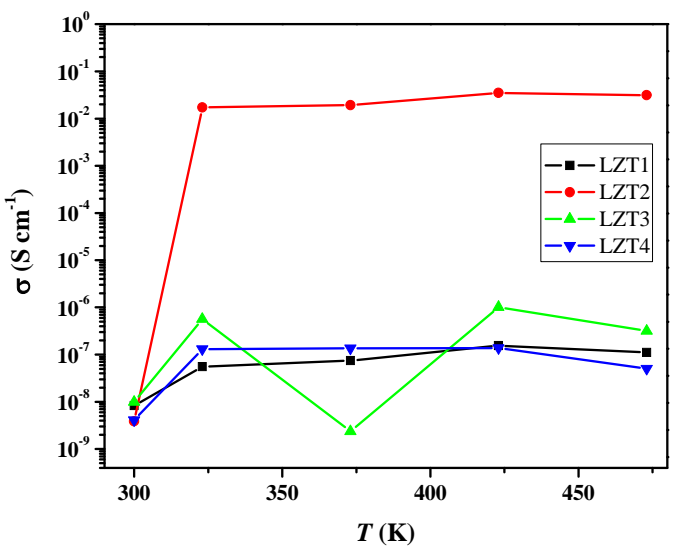

Fig. 3. Temperature dependence of the ionic conductivity for the glass electrolytes at $54 \mathrm{~Hz}$

Fig. 4 displays the frequency dependent ionic conductivity of the electrolytes at $323 \mathrm{~K}$. The ionic conductivity of the un-doped electrolyte exhibits more fluctuations compared to the doped samples. No significant change in the conductivity appeared due to the increase in the frequency. The conductivities of all glass electrolytes are in the range of $10^{-9}$ and $10^{-5} \mathrm{~S} \mathrm{~cm}^{-1}$, except LZT2 electrolyte. Its conductivity remains stable with increasing frequency up to $10^{4} \mathrm{~Hz}$. The ions vibrate vigorously and the covalent bonds in the electrolytes are broken with the increase of frequency, so the ions can move through unperfect NBO under the influence of an external electric field (applied voltage).

Fig. 5 depicts the $\mathrm{Li}_{2} \mathrm{O}$ concentrations dependent ionic conductivity of the glass electrolyte at frequency 54 $\mathrm{Hz}$ and temperature of $323 \mathrm{~K}$. The un-doped glass electrolyte is found to acquire very low ionic conductivity $\left(\sim 5.56 \times 10^{-8} \mathrm{~S} \mathrm{~cm}^{-1}\right)$ due to absence of Li-ions. This condition is also shown by the electrolytes containing 10 and $15 \mathrm{~mol} \%$ of $\mathrm{Li}_{2} \mathrm{O}$. High $\mathrm{Li}_{2} \mathrm{O}$ concentrations in the electrolyte decreased the ionic mobility due to collision upon applying a tiny electric field. The ion undergoes a collision and loses some or all of its kinetic energy. Consequently, its velocity is diminished followed by a decreasing mobility and ionic conductivity. The glass electrolyte containing $5 \mathrm{~mol} \%$ of $\mathrm{Li}_{2} \mathrm{O}$ exhibited good performance with the ionic conductivity of $1.72 \times 10^{-2} \mathrm{~S} \mathrm{~cm}^{-}$ ${ }^{1}$. Furthermore, the mobility reached a maximum value at low impurity concentrations [17].

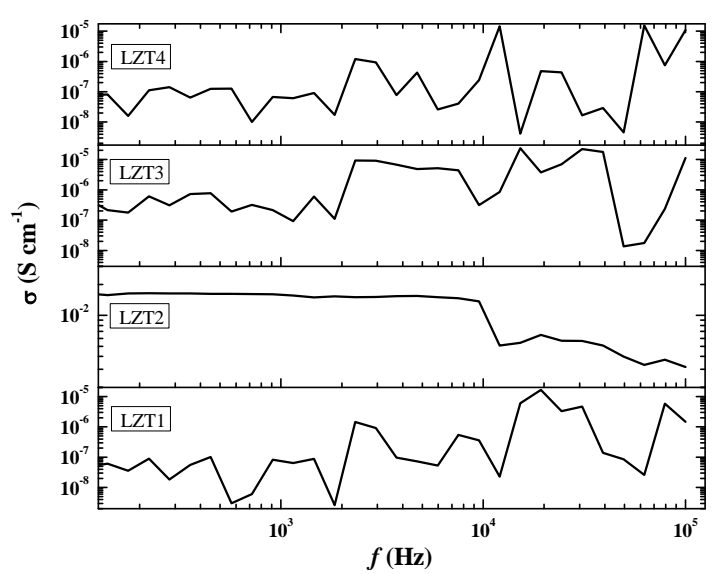

Fig. 4. Ionic conductivity of the glass electrolytes as function of frequency at $323 \mathrm{~K}$

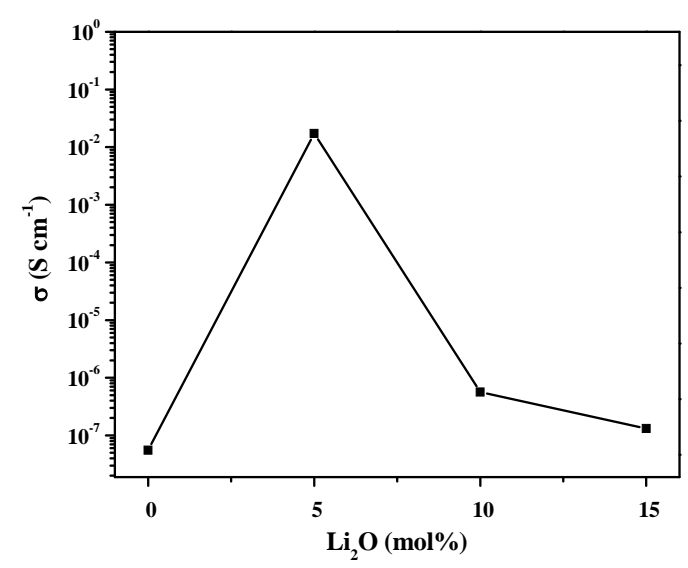

Fig. 5. $\mathrm{Li}_{2} \mathrm{O}$ concentration dependent ionic conductivity for the glass electrolytes at $54 \mathrm{~Hz}$ and $323 \mathrm{~K}$

In is well known that the ionic conductivity as a function of temperature can be described by Arrhenius equation [1820],

$\sigma=\frac{\sigma_{0}}{T} \exp \left(-\frac{E_{a}}{k T}\right)$ 
where $\sigma_{0}$ is pre-exponesial factor $\left(\mathrm{S} \mathrm{m}^{-1}\right), E_{a}$ is the activation energy $(\mathrm{J}), T$ is the temperature $(\mathrm{K})$ and $k$ is the Boltzmann constant $\left(\mathrm{J} \mathrm{K}^{-1}\right)$. The value of $\sigma_{0}$ depends on charge carrier concentration $n$, amount of charge $q$ and attempt jump frequency together with jump distance. The energy renders information about the number of free ion and its mobility. The energy is determined by plotting $\log (\sigma T)$ vs. $\frac{1}{T}$ and yields

$$
\log (\sigma T)=\log \left(\sigma_{0}\right)-\left(\frac{E_{a}}{k}\right) \frac{1}{T}
$$

The energy of total conductivity in the temperature range of $300-473 \mathrm{~K}$ is obtained from the gradient of the plot and the intercept along y-axis provides the value of $\sigma_{0}$.

Fig. 6 reveals the changes of $\log (\sigma T)$ as a function of inverse temperatures for the electrolytes. Their slopes are high at low temperature and decrease gradually with increase in temperature. At low temperatures, the energy is used by the ions to get them released from the covalent bond and acquire their mobility. Meanwhile, at high temperature, the energy is used only to make them mobile. The highest value of activation energy for the total conductivities is discerned to be $3.85 \times 10^{-1} \mathrm{eV}$ for LZT2 electrolyte containing $5 \mathrm{~mol} \%$ of $\mathrm{Li}_{2} \mathrm{O}$.

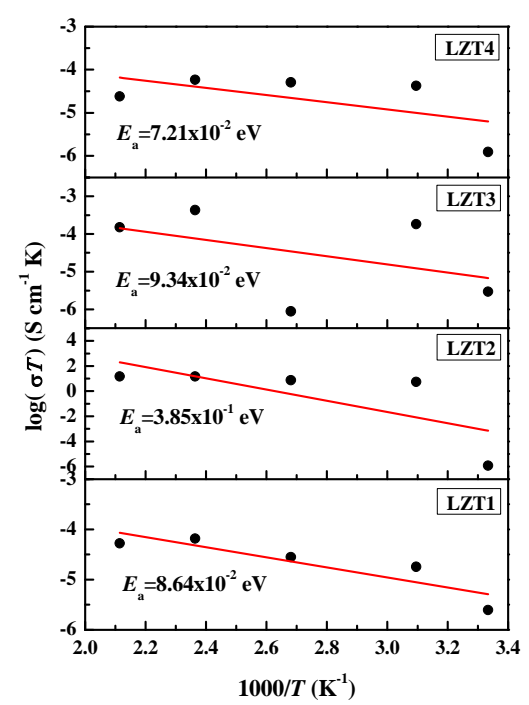

Fig. 6. Arrhenius plots of $\log (\sigma T)$ against inverse temperature (1/T) for the glass electrolytes at $54 \mathrm{~Hz}$

\section{CONCLUSION}

To the best of our knowledge, for the first time a new type of the zinc-tellurite glass electrolytes containing various $\mathrm{Li}_{2} \mathrm{O}$ concentrations are prepared via melt quenching method at $800{ }^{\circ} \mathrm{C}$. The obtained electrolytes are indeed amorphous in nature with superior thermal stability factor above $100{ }^{\circ} \mathrm{C}$. The frequency of AC voltage is found to have insignificant influence to the ionic conductivity of the electrolytes. Although, theoretically it can generate ionic vibration and break the covalent bond between Li-ion and neighbouring atoms. The ionic conductivity is observed to increase with increasing temperature up to 423 $\mathrm{K}$ at low concentration of $\mathrm{Li}_{2} \mathrm{O}$. Meanwhile, the slope decreases gradually with the increase in temperature. The best performance is exhibited by the electrolyte containing $5 \mathrm{~mol} \%$ of $\mathrm{Li}_{2} \mathrm{O}$, which offered the admirable ionic conductivity of $1.72 \times 10^{-2} \mathrm{~S} \mathrm{~cm}^{-1}$ and excellent activation energy of $3.85 \times 10^{-1} \mathrm{eV}$ at temperature of $323 \mathrm{~K}$ and $54 \mathrm{~Hz}$. It is demonstrated that the temperature, frequency and $\mathrm{Li}_{2} \mathrm{O}$ concentrations notably modified the structural features, thermal stability, and ionic conductivity of zinc-tellurite glass based electrolytes. The excellent features of the prepared electrolytes suggest that our materials are useful for battery manufacturing.

\section{ACKNOWLEDGEMENTS}

This work was supported by Universitas Jenderal Soedirman and DIKTI through Stranas Research Grant (Kept. 4302/UN23.10/PN.01.00/2014).

\section{REFERENCES}

[1] Y. Wang, G. Cao, Adv. Mater. 20 (2008) 2251.

[2] A. Odani, A. Nimberger, B. Markovsky, E. Sominski, E. Levi, V.G. Kumar, et al., J. Power Sources. 119-121 (2003) 517.

[3] J. Kim, S. Lee, D. Shin, J. Ceram. Process. Res. 8 (2007) 208.

[4] Y. Ooura, N. Machida, T. Uehara, S. Kinoshita, M. Naito, T. Shigematsu, et al., Solid State Ionics. 5 (2013) 6.

[5] C.E. Kim, H.C. Hwang, M.Y. Yoon, B.H. Choi, H.J. Hwang, J. Non. Cryst. Solids. 357 (2011) 2863.

[6] M. Tatsumisago, A. Hayashi, J. Non. Cryst. Solids. 354 (2008) 1411.

[7] N. Machida, R. Fuchida, T. Minami, Solid State Ionics. 35 (1989) 295.

[8] T. Ohtomo, A. Hayashi, M. Tatsumisago, Y. Tsuchida, S. Hama, K. Kawamoto, J. Power Sources. 233 (2013) 231.

[9] A. Hayashi, T. Ohtomo, F. Mizuno, K. Tadanaga, M. Tatsumisago, Electrochem. Commun. 5 (2003) 701.

[10] M.R. Sahar, N. Noordin, J. Non-Cryst. Solids. 184 (1995) 137.

[11] W. Widanarto, M.R. Sahar, S.K. Ghoshal, R. Arifin, M.S. Rohani, K. Hamzah, et al., Mater. Chem. Phys. 138 (2013) 174.

[12] W. Widanarto, M.R. Sahar, S.K. Ghoshal, R. Arifin, M.S. Rohani, M. Effendi, Mater. Lett. 108 (2013) 289.

[13] S. Akmar Roslan, Rahim Sahar, Rohani, K. Hamzah, Adv. Mater. Res. 501 (2012) 96.

[14] A. Kaur, A. Khanna, C. Pesquera, F. González, V. Sathe, J. NonCryst. Solids. 356 (2010) 864.

[15] W. Widanarto, M.R. Sahar, S.K. Ghoshal, R. Arifin, M.S. Rohani, Berk. Fis. 16 (2013) 95.

[16] V.K. Deshpande, IOP Conf. Ser. Mater. Sci. Eng. 2 (2009) 012011.

[17] S.M. Sze, Semiconductor Devices, Physics and Technology, $2^{\text {nd }}$ ed. John Wiley \& Sons, Inc., New York, 1985.

[18] K. Muthukkumaran, P. Kuppusami, E. Mohandas, V.S. Raghunathan, Int. Symp. Res. Students Mater. Sci. Eng., 2004.

[19] C. Zhang, C. Li, G. Zhang, X. Ning, Mater. Sci. Eng. 137 (2007) 24.

[20] L. Ying, G. Jiang-Hong, T. Zi-Long, X. Yu-Sheng, Z. Zhong-Tai, Acta Phys.-Chim. Sin. 17 (2001) 792. 